\title{
(C) OPEN ACCESS \\ How well do we currently care for our dying patients in acute hospitals: the views of the bereaved relatives?
}

\author{
Catriona Rachel Mayland, ${ }^{1}$ Helen Mulholland, ${ }^{1}$ Maureen Gambles, ${ }^{1}$ \\ John Ellershaw, ${ }^{1}$ Kevin Stewart ${ }^{2}$
}

'Marie Curie Palliative Care Institute Liverpool (MCPCIL), Cancer Research Centre, University of Liverpool, Liverpool, UK

${ }^{2}$ Clinical Effectiveness and Evaluation Unit, Royal College of Physicians, London, UK

\section{Correspondence to}

Dr Catriona Rachel Mayland, Marie Curie Palliative Care Institute Liverpool (MCPCIL), Cancer Research Centre, University of Liverpool, 200 London Road, Liverpool L3 9TA, UK:

catriona.mayland@liverpool. ac.uk

Received 7 November 2014 Revised 11 December 2015 Accepted 1 September 2016 Published Online First

17 January 2017

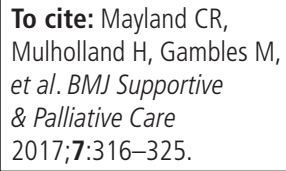

\begin{abstract}
Background The National Care of the Dying Audit-Hospitals (NCDAH) is used as a method to evaluate care for dying patients in England. An additional component to the 2013/2014 audit was the Local Survey of Bereaved Relatives Views using the 'Care Of the Dying Evaluation' (CODE) questionnaire.
\end{abstract}

Aim Within the context of the NCDAH audit, to evaluate quality of care provided to dying patients and their families in acute hospitals from the perspective of bereaved relatives.

Design Postbereavement survey to bereaved relatives.

Setting/participants For acute hospitals wishing to participate, consecutive 'expected' adult deaths occurring between 1 May and 30 June 2013 were identified and the CODE questionnaire was sent to the next-of-kin. Results From 3414 eligible next-of-kin, 95 (2.8\%) were excluded due to being involved in a complaint procedure and 1006 (29.5\%) due to insufficient next-of-kin details. From the remaining 2313 potential participants, 858 returned a completed CODE questionnaire (37.1\% response rate). Generally, symptoms were perceived to be well controlled with 769 (91\%) participants reporting that either no pain was present or only there 'some of the time'. Unmet information needs, however, was a recognised area for improvement, for example, 230 (29\%) reporting having a discussion about hydration would have been beneficial.

Conclusions Adopting a postbereavement survey to NCDAH appears to be feasible, acceptable and a valuable addition. On the whole, the majority of participants reported good or excellent care. A small but significant minority, however, perceived poor quality of patient care with clear and timely communication urgently needed.

\section{BACKGROUND}

Care of dying patients is part of the core business for acute hospitals. Although a European study demonstrated national variations in the proportion of hospital deaths, ${ }^{1}$ a significant proportion of patients within many developed countries, including the UK, continue to die in hospitals. $^{2-4}$ Indeed, for some patients, the acute hospital is their preferred place of care and death, as home represents a 'lonely and frightening place'. 5 A recent Scottish study, establishing the likelihood of death within 12 months for a cohort of hospital inpatients, showed $28.8 \%$ patients died during this period. Deaths during the actual admission accounted for $32.3 \%$ of all deaths during the follow-up year. ${ }^{6}$ Hence, ensuring good quality of care and support is provided for all dying patients within the acute hospital remains fundamentally important. This was highlighted further within the Neuberger Review of care of the dying in England which recommended a need for improved skills and competencies for clinical staff caring for dying patients within the hospital. ${ }^{7}$ The future plan within the UK is for individualised patient end-of-life care plans. There are concerns, however, about the potential gaps in the provision of patient care while these are being developed and the lack of support for generic healthcare staff $^{8}$ with the withdrawal of the Liverpool Care Pathway for the Dying Patient (LCP), an integrated care pathway which was used to support patient care in the last days of life. ${ }^{9}$

In order to improve care, we need to be able to evaluate the current quality of 
care. ${ }^{10}$ One method adopted within England to help evaluate care for dying patients within the acute hospital setting is the National Care of the Dying AuditHospitals (NCDAH) programme. ${ }^{11}$ The programme initially started in 2006/2007 and to date four NCDAH Reports have been published. The process involves a retrospective audit of organisational and clinical elements of care in the dying phase and enables clinical teams and executive boards of individual hospitals to measure themselves against a 'national benchmark' of care for the dying in acute hospitals. This helps identify areas of unmet need and issues relating to organisational or environmental factors, which can be formulated locally into an action plan as part of a continuous quality improvement programme.

An additional and optional component to the NCDAH, England 2013/2014 was the inclusion of the Local Survey of Bereaved Relatives Views (henceforth referred to as 'Local Survey'). This provided acute hospitals with the opportunity to seek the views of bereaved relatives or friends about their family members' 'last episode of hospital care'. These views were captured using 'Care Of the Dying Evaluation' (CODE), ${ }^{12}$ a 41 -item self-completion postal questionnaire. CODE represents a shortened, more userfriendly version of the original instrument, 'Evaluating Care and Health Outcomes-for the Dying' (ECHO-D) and both questionnaires specifically link to key components of best practice for 'care of the dying' (last days of life and immediate postbereavement period). Additionally, ECHO-D and CODE have been assessed for validity and reliability. ${ }^{12-15}$ Individual questions ask about aspects of symptom control, communication, provision of fluids, place of death, emotional and spiritual support using dichotomous and Likert-scale response options.

\section{AlIM}

Within the context of the NCDAH, England 2013/ 2014 audit, the aim was to evaluate the current quality of care provided to dying patients and their families in acute hospitals from the perspective of bereaved relatives. In particular, the key focus was on:

- Symptom control

- Communication

- Dignity and respect and family support

In addition, exploration of initial comparisons between the bereaved relatives' perceptions about these key aspects of care with the overall findings from the clinical case note review was sought.

\section{METHODS}

The overall study design was a postbereavement survey, using the 'CODE' questionnaire, with the next-of-kin to patients who had died within the acute hospital setting.
First, a case note review was conducted and the following inclusion criteria were applied:

- patient over 18 years of age;

- death occurred in acute hospital between 1 May and 31 July 2013; and

- patients under the care of the hospital for more than 24 hours prior to death.

Initially, patients were excluded by individual hospitals governance teams where the death was sudden or unexpected, for example, death occurred in accident and emergency department; as a result of accident or overdose; suicide was suspected; or where cause of death unknown. The clinical audit lead of each hospital then reviewed on a case-by-case basis those deaths where the following potentially excludable ICD-10 codes were present:

- acute myocardial infarction (I21, I22);

- pulmonary embolism (I26);

- pulmonary aneurysm (I281);

- sudden cardiac death (I461);

- aortic aneurysm (I71);

- injury, poisoning or external causes (S00-T98).

This process was supported and guided by information published from the National End of Life Care Intelligence Network. ${ }^{16}$ The case note review comprised of collecting anonymised demographic data (gender, age, primary diagnosis, ethnicity, religious affiliation) for each patient, as well as clinical information identified to reflect best care for the dying patient, for consecutive deaths during May 2013. Participating sites with fewer than 50 cases for May could continue to include consecutive cases from June and July until they had at least 50 audit cases or had reached 31 July with fewer than 50 cases if that was the maximum eligible number available. Data collected included whether or not the patient was recognised to be dying by the multidisciplinary team; and whether or not there was documented communication about the patients' plan of care in the dying phase. Additionally, data were collected about whether or not anticipatory medications were prescribed for likely end-of-life symptoms; whether there were clinical protocols in place to guide this prescribing; and whether or not there was documented communication about key end-of-life discussions.

For the Local Survey, the consecutive sample of deaths matched the above inclusion and exclusion criteria with the exception that only those deaths occurring between 1 May and 30 June were included. All cases where a formal complaint was pending were excluded due to the fact that the family member had already taken steps to express dissatisfaction with care and sending the CODE questionnaire could be perceived as insensitive. For hospitals which chose to undertake the Local Survey, bereaved relatives were invited to complete the CODE questionnaire no less than 3 months following the death. There was also an 
option for online completion. Data about hospitals who undertook the Local Survey were compared with those who did not, for example, size of hospital, number of deaths.

The key CODE outcome questions were:

- How much of the time was $\mathrm{s} / \mathrm{he}$ treated with respect and dignity in the last 2 days of life? (separate questions for doctors and nursing staff)

- Overall, in your opinion, were you adequately supported during his/her last 2 days of life?

In terms of secondary outcomes, for the assessment of symptom control, perceptions regarding pain, restlessness and retained respiratory tract secretions were assessed. Furthermore, to assess communication, perceptions about the ability of staff to listen and discuss the patients' condition; their involvement in decisionmaking; and whether or not end-of-life information needs were met were asked within the CODE questionnaire.

\section{Analysis}

Quantitative data were analysed descriptively using SPSS V.19 and presented as proportions (\%) and median values (with IQR) where applicable. Comparison between findings between the Local Survey and the case note review was also analysed descriptively.

\section{Ethical approval}

The NCDAH concurs with the definition of audit as stipulated by the Health Research Authority and as such, ethical approval was not required. ${ }^{17}$ Participating sites of the Local Survey were advised to ensure the process was compliant with their local Quality Governance Framework.

\section{RESULTS}

\section{Sample for case note review}

From 130 acute hospital trusts (90\% of all eligible), 6580 patient data sets were submitted to form the national clinical sample (figure 1). More detailed information about this sample has already been documented. ${ }^{18}$

\section{Sample for local survey}

Initially, $93(72 \%)$ of all Trusts registered to participate in the Local Survey. Thirty-six Trusts (27\%) of those participating in the clinical case note audit review, however, proceeded and undertook the local survey of bereaved relatives. From 3414 eligible next-of-kin, 95 (2.8\%) were excluded due to being involved in a symptom procedure. A subsequent 1006 were excluded due to insufficient next-of-kin details, for example, missing postal addresses. This left 2313 potential participants, from whom 858 bereaved relatives (henceforth, named as 'participants') returned a completed CODE questionnaire $(37.1 \%$ response rate) (figure 2).

\section{Comparison between Trusts which completed CODE and those who did not}

CODE and non-CODE Trusts appeared similar in size in terms of the:

- number of adult wards (median 26 vs 27),

- adult beds (median 571 vs 623 ),

- adult single occupancy (median 126 vs 124),

- adult deaths in financial year (median 1306 vs 1316),

- adult deaths in National aggregate data collection period (median 103 vs 106),

- adult deaths occurring in the national aggregate data collection period in those hospitals entered into the clinical audit (median 96 vs 98). ${ }^{18}$

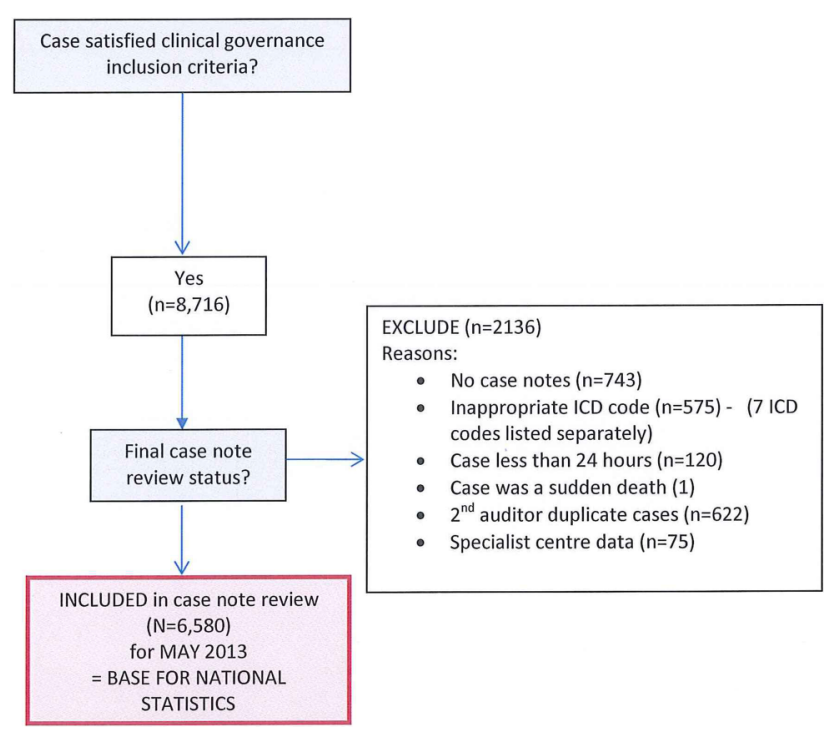

Figure 1 (National) Case note review data for May 2013. 


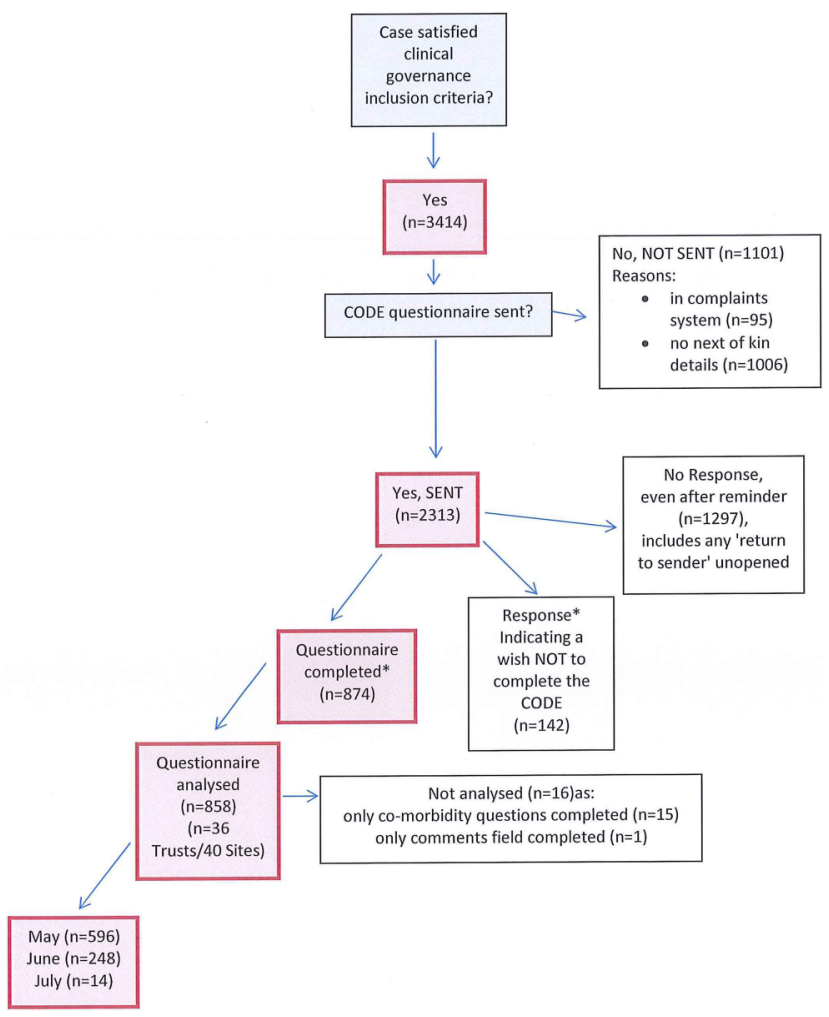

Figure 2 (National) Analysis of code survey questionnaire: 1 May-31 July 2013.

\section{Demographic details of deceased patients and participants within local survey}

The deceased patients were more likely to be aged 70 years or older $(n=674,78.6 \%)$, be of White British ethnicity $(n=780,96 \%)$ and have a Christian affiliation $(n=674,84 \%)$. There was a fairly equal gender split (number of males $=395,51 \%$ ) (table 1 ). Approximately one-third $(n=265,31 \%)$ of deceased patients had a cancer diagnosis.

Participants were mainly women $(n=523,65 \%)$, mainly aged either between 60 and 69 years $(n=248$, $30 \%)$ or 50 and 59 years $(n=194,24 \%)$, and were a spouse/partner $\quad(n=387,47 \%)$ or son/daughter $(n=366,44 \%)$ (table 2$)$. The majority of participants were of White British ethnicity $(n=794,97 \%)$, and had a Christian religious affiliation religion $(n=676$, $84 \%)$.

\section{Symptom control}

Seven hundred and sixty-nine (91\%) participants perceived that their family member either had no pain or was only present 'some of the time'. Restlessness and retained respiratory tract secretions were reported as being more prevalent compared with pain as 112 (13\%) and $130(16 \%)$ participants reporting restlessness and retained respiratory tract secretions were present 'all the time'. On the whole, however, participants perceived that healthcare teams had made efforts to control symptoms, with only 34 (4\%), 54 $(7 \%)$ and $59(7 \%)$ saying that staff did not do enough to control pain, restlessness and retained respiratory tract secretions, respectively (table 3 ).

Comparison with the results from the organisational element of the NCDAH $(n=150$ sites) showed 98\% of participating Trusts reported they had clinical protocols in place for anticipatory prescribing of medications to help control the most frequent symptoms that can occur with dying patients (pain, dyspnoea, nausea, agitation and retained respiratory tract secretions). ${ }^{18}$

Additionally, $81 \%, 72 \%$ and $65 \%$ of patient cases within the case note review had documented evidence that medication was prescribed to help with pain, restlessness and retained respiratory tract secretions, respectively at the time of the patient's death (table 4).

\section{Communication}

Six hundred and sixty-six (74\%) participants reported that they were told that their family member was likely to die. Although discussions about key issues relating to end-of-life care occurred, for example, provision of fluids and knowing what to expect as their family member approached death, a proportion of participants reported they would have found such discussions beneficial.

In particular, 230 (29\%) would have found benefit in having a discussion about hydration and 377 (46\%) would have benefit in knowing more about what to expect as their family member was dying (table 3 ).

One hundred and thirty-one (16\%) and 121 (14\%) participants responded 'disagree' or 'strongly disagree' 


\section{Research}

Table 1 Demographic information for deceased patients

\begin{tabular}{|c|c|c|c|c|}
\hline \multicolumn{3}{|c|}{ Demographic for deceased patients within local survey $(n=858)$} & \multicolumn{2}{|c|}{$\begin{array}{l}\text { Demographic for deceased } \\
\text { patients within case note } \\
\text { review ( } n=6580)\end{array}$} \\
\hline & $\mathrm{n}$ & $\%$ & $\mathrm{n}$ & $\%$ \\
\hline \multicolumn{5}{|c|}{ Diagnosed illnesses during the last days of life $(n=858)$} \\
\hline Cancer (including leukaemia and lymphoma) & 265 & 31 & 1546 & 23 \\
\hline Heart failure & 228 & 27 & 499 & 8 \\
\hline COPD & 162 & 19 & 439 & 7 \\
\hline End-stage renal (or kidney) disease & 118 & 14 & 114 & 2 \\
\hline Dementia & 114 & 13 & 181 & 3 \\
\hline Motor neuron disease & 4 & 0.5 & 57 & 1 \\
\hline Do not know & 30 & 3 & NA & NA \\
\hline Something else & 235 & 27 & 3744 & 57 \\
\hline Age in years $(n=816)$ & \multicolumn{4}{|c|}{ Median patient age 82 (IQR 73-88) } \\
\hline $18-19$ & 0 & 0 & 0 & 5 \\
\hline $20-29$ & 1 & 0.1 & 0 & 10 \\
\hline $30-39$ & 1 & 0.1 & 0 & 33 \\
\hline $40-49$ & 6 & 1 & 2 & 122 \\
\hline $50-59$ & 32 & 4 & 5 & 299 \\
\hline $60-69$ & 102 & 13 & 11 & 697 \\
\hline $70-79$ & 218 & 27 & 24 & 1568 \\
\hline $80+$ & 456 & 56 & 58 & 3846 \\
\hline \multicolumn{5}{|l|}{ Ethnicity $(n=809)$} \\
\hline White British & 780 & 96 & 89 & 5870 \\
\hline Mixed white/black Caribbean & 0 & 0 & 0 & 24 \\
\hline White Irish & 8 & 1 & 1 & 58 \\
\hline Mixed white/black African & 1 & 0.1 & 0 & 1 \\
\hline White other & 14 & 2 & 2 & 121 \\
\hline Mixed white/Asian & 0 & 0 & 0 & 1 \\
\hline Indian & 1 & 0.1 & 1 & 61 \\
\hline Mixed other & 0 & 0 & 0 & 13 \\
\hline Pakistani & 0 & 0 & 1 & 39 \\
\hline Black Caribbean & 0 & 0 & 1 & 55 \\
\hline Bangladeshi & 0 & 0 & 0 & 11 \\
\hline Black African & 2 & 0.2 & 1 & 35 \\
\hline Asian other & 1 & 0.1 & 1 & 56 \\
\hline Black other & 0 & 0 & 0 & 3 \\
\hline None of these & 2 & 0.2 & 4 & 232 \\
\hline \multicolumn{5}{|l|}{ Gender $(n=782)$} \\
\hline Male & 395 & 51 & 49 & 3248 \\
\hline Female & 387 & 49 & 51 & 3332 \\
\hline \multicolumn{5}{|l|}{ Religious affiliation ( $n=805$ ) } \\
\hline None & 109 & 14 & 29 & 1882 \\
\hline Christian & 678 & 84 & 65 & 4252 \\
\hline Hindu & 0 & 0 & 1 & 46 \\
\hline Buddhist & 2 & 0.2 & 0 & 16 \\
\hline Jewish & 5 & 1 & 1 & 49 \\
\hline Muslim & 1 & 0.1 & 1 & 94 \\
\hline Sikh & 1 & 0.1 & 0 & 24 \\
\hline Any other religion & 9 & (9) & 3 & 217 \\
\hline
\end{tabular}


Table 2 Demographic information for participants who completed CODE questionnaire

\begin{tabular}{|c|c|c|}
\hline \multicolumn{3}{|l|}{ Demographic $(n=858)$} \\
\hline & $\mathrm{n}$ & $\%$ \\
\hline \multicolumn{3}{|l|}{ Relationship to patient $(n=825)$} \\
\hline Husband/wife/partner & 387 & 47 \\
\hline Son/daughter & 366 & 44 \\
\hline Brother/sister & 24 & 3 \\
\hline Son-in-law/daughter-in-law & 6 & 1 \\
\hline Parent & 11 & 1 \\
\hline Friend & 1 & 0.1 \\
\hline Neighbour & 1 & 0.1 \\
\hline Staff in nursing or residential home & 0 & 0 \\
\hline Warden (sheltered accommodation) & 1 & 0.1 \\
\hline Other & 28 & 3 \\
\hline \multicolumn{3}{|l|}{ Age in years $(n=822)$} \\
\hline $18-19$ & 0 & 0 \\
\hline $20-29$ & 5 & 1 \\
\hline $30-39$ & 8 & 1 \\
\hline $40-49$ & 80 & 10 \\
\hline $50-59$ & 194 & 24 \\
\hline $60-69$ & 248 & 30 \\
\hline $70-79$ & 179 & 22 \\
\hline $80+$ & 108 & 13 \\
\hline \multicolumn{3}{|l|}{ Ethnicity $(n=817)$} \\
\hline White British & 794 & 97 \\
\hline Mixed white/black Caribbean & 2 & 0.2 \\
\hline White Irish & 6 & 1 \\
\hline Mixed white/black African & 1 & 0.1 \\
\hline White other & 7 & 1 \\
\hline Mixed white/Asian & 1 & 0.1 \\
\hline Indian & 1 & 0.1 \\
\hline Mixed other & 0 & 0 \\
\hline Pakistani & 0 & 0 \\
\hline Black Caribbean & 2 & 0.2 \\
\hline Bangladeshi & 0 & 0 \\
\hline Black African & 1 & 0.1 \\
\hline Asian other & 1 & 0.1 \\
\hline Black other & 0 & 0 \\
\hline None of these & 1 & 0.1 \\
\hline \multicolumn{3}{|l|}{ Gender $(n=801)$} \\
\hline Male & 278 & 35 \\
\hline Female & 523 & 65 \\
\hline \multicolumn{3}{|l|}{ Religious affiliation $(n=806)$} \\
\hline None & 117 & 15 \\
\hline Christian & 676 & 84 \\
\hline Hindu & 0 & 0 \\
\hline Buddhist & 3 & 0.4 \\
\hline Jewish & 5 & 1 \\
\hline Muslim & 1 & 0.1 \\
\hline Sikh & 1 & 0.1 \\
\hline Any other religion & 3 & 0.4 \\
\hline
\end{tabular}

as to whether nurses and doctors had time to listen and discuss their family member's condition with them. Almost one-quarter of participants $(n=200$, 24\%) perceived that they were not involved at all in decision-making.

When compared with the case note review, a greater proportion of case notes (93\%) had documented evidence of discussions with the relatives about the fact that their family member was recognised to be dying (table 4). Specific discussions about the plan of care for this phase of the patients' illness, however, were only documented in $73 \%$ of case notes. Additionally, documented discussions with the family members about hydration options and care were only specifically documented in $36 \%$ of case notes.

\section{Overall impressions}

Generally, participants perceived that their family member was treated with dignity and respect. Six hundred and forty (79\%) participants perceived that doctors 'always' or 'most of the time' treated their family member with dignity and respect. Similarly, $708(86 \%)$ of participants gave these responses for nursing staff. Seven hundred and ninety-three (76\%) participants perceived themselves to be adequately supported (table 5).

\section{DISCUSSION}

This is the first time that NCDAH has adopted a Local Survey of Bereaved Relatives' Views and this appears to be a feasible, and generally acceptable and useful addition to the existing components of the national audit. On the whole, the majority of the participants reported good or excellent care. More concerning, however, a small but significant minority perceived poor quality of patient care and almost onequarter of participants reported inadequate support in the last days of life. Aspects of symptom control were perceived to be better met compared with communication. In particular, having more time to discuss their family members' condition with members of the healthcare team, as well as having specific information about hydration and what to expect when someone is dying are identified areas where needs could be better met.

There were certain recognised limitations which will now be detailed. First, not all Trusts participated in the local survey. The majority registered to participate in this component ( $72 \%$ of Trusts), but due to factors including time constraints, they were unable to complete this audit component within the given time frame. Factoring this challenge into future audits and being pro-active in specifically providing additional support and highlighting deadlines with reminders for the Local Survey would be aspects to take forward. It 
Table 3 Aspects of symptom control and communication with the healthcare team (HCT) as perceived by the bereaved relatives*

Local survey of bereaved relatives $(n=858)$

\begin{tabular}{lrr}
\hline The control of pain and other symptoms & n & \% \\
\hline 10. In your opinion, during the last 2 days, did s/he appear to be in pain? \\
( $\mathrm{n}=845)$ \\
Yes, all of time & 76 & 9 \\
Yes, some of time & 335 & 40 \\
No, s/he did not appear to be in pain & 434 & 51 \\
Missing data & 13 & 1.5
\end{tabular}

11. In your view, did the doctors and nurses do enough to help relieve the pain? $(\mathrm{n}=833)$

$\begin{array}{lrr}\text { Yes, all of time } & 437 & 52 \\ \text { Yes, some of time } & 193 & 23 \\ \text { No, not at all } & 34 & 4 \\ \text { Not applicable, s/he was not in pain } & 169 & 20 \\ \text { Missing data } & 25 & 2.9\end{array}$

12. In your opinion, during the last 2 days, did s/he appear to be restless? $(n=844)$

$\begin{array}{lrc}\text { Yes, all of time } & 112 & 13 \\ \text { Yes, some of time } & 399 & 47 \\ \text { No, s/he did not appear to be restless } & 333 & 39 \\ \text { Missing data } & 14 & 1.6\end{array}$

13. In your view, did the doctors and nurses do enough to help relieve the restlessness? $(n=830)$

$\begin{array}{lrr}\text { Yes, all of time } & 282 & 34 \\ \text { Yes, some of time } & 255 & 31 \\ \text { No, not at all } & 54 & 7 \\ \text { Not applicable, s/he was not restless } & 239 & 29 \\ \text { Missing data } & 28 & 3.3\end{array}$

14. In your opinion, during the last 2 days, did s/he appear to have a 'noisy rattle' to his/her breathing? $(n=833)$

$\begin{array}{lll}\text { Yes, all of time } & 130 & 16 \\ \text { Yes, some of time } & 274 & 33 \\ \text { No, s/he did not have a 'noisy rattle' to the breathing } & 429 & 52\end{array}$

$\begin{array}{lll}\text { Missing data } & 25 & 2.9\end{array}$

15. In your view did the doctors and nurses do enough to help relieve the 'noisy rattle' to his/her breathing? $(n=807)$

$\begin{array}{lrc}\text { Yes, all of time } & 188 & 23 \\ \text { Yes, some of time } & 169 & 21 \\ \text { No, not at all } & 59 & 7 \\ \text { Not applicable, s/he was not restless } & 391 & 48 \\ \text { Missing data } & 51 & 5.9 \\ \text { Communication with the HCT } & \text { N } & \%\end{array}$

8. The nurses had time to listen and discuss his/her condition with me

$\begin{array}{lrr}\text { Strongly agree } & 290 & 34 \\ \text { Agree } & 336 & 40 \\ \text { Neither agree nor disagree } & 90 & 11 \\ \text { Disagree } & 82 & 10 \\ \text { Strongly disagree } & 49 & 6 \\ \text { Missing data } & 11 & 1.3\end{array}$

9. The doctors had time to listen and discuss his/her condition with me

\begin{tabular}{lll} 
Strongly agree & 284 & 34 \\
Agree & 326 & 39 \\
Neither agree nor disagree & 101 & 12 \\
\hline
\end{tabular}

Continued
Table 3 Continued

Local survey of bereaved relatives $(n=858)$

\begin{tabular}{lcc}
\hline The control of pain and other symptoms & $\mathrm{n}$ & $\%$ \\
\hline Disagree & 78 & 9 \\
Strongly disagree & 43 & 5 \\
Missing data & 26 & 3.0
\end{tabular}

16. During the last 2 days how involved were you with the decisions about his/her care and treatment? $(n=839)$

$\begin{array}{lrc}\text { Very involved } & 402 & 48 \\ \text { Fairly involved } & 237 & 28 \\ \text { Not involved } & 200 & 24 \\ \text { Missing data } & 19 & 2.2\end{array}$

17. Did any of the healthcare team discuss with you whether giving fluids through a 'drip' would be appropriate in the last 2 days of life? $(n=818)$

$\begin{array}{lrc}\text { Yes } & 323 & 39 \\ \text { No } & 411 & 50 \\ \text { Do not know } & 84 & 10 \\ \text { Missing data } & 40 & 4.7\end{array}$

18. Would a discussion about the appropriateness of giving fluids through a 'drip' in the last 2 days of life have been helpful? $(n=791)$

$\begin{array}{lrr}\text { Yes } & 279 & 35 \\ \text { No } & 230 & 29 \\ \text { Not applicable, we had these types of discussion } & 282 & 36 \\ \text { Missing data } & 67 & 7.8\end{array}$

23. Before s/he died, were you told s/he was likely to die?

$\begin{array}{lrr}\text { Yes } & 616 & 74 \\ \text { No } & 219 & 26 \\ \text { Missing data } & 23 & 2.7\end{array}$

24. Did a member of the healthcare team talk to you about what to expect when s/he was dying (eg, symptoms that may arise)?

$\begin{array}{lrc}\text { Yes } & 377 & 46 \\ \text { No } & 438 & 54 \\ \text { Missing data } & 43 & 5.0\end{array}$

25. Would a discussion about what to expect when s/he was dying have been helpful?

\begin{tabular}{lrc} 
Yes & 355 & 44 \\
No & 141 & 17 \\
Not applicable, we had these types of discussion & 314 & 39 \\
Missing data & 48 & 5.6 \\
\hline
\end{tabular}

*Missing data are presented as exact numbers (and percentages) for each of the questions within the tables. The cases of missing data were then excluded from all subsequent analysis and 'valid' percentages were calculated. Hence, the percentages within the tables are $>100 \%$.

is noteworthy, however, that the comparative analysis of the organisational structure of Trusts completing the Local Survey with those who did not showed many similarities. Overall, the response rate from the bereaved relatives was $37.1 \%$ which is in keeping with some previous studies of this nature. ${ }^{14} 19$ The most recent UK VOICES national survey had a higher response rate of $46 \%$ but 3 mail-outs were permitted. ${ }^{20}$ Second, the demographic details of those who chose not to participate are not available, limiting the ability to state the representativeness of this sample compared with the population as a whole. Additionally, we excluded those who had submitted a 
Table 4 Clinical audit results about anticipatory prescribing for symptom management and key pertinent end-of-life discussions

Clinical audit results $(n=6580)$

n $\%$

5a. At the time of the patient's death, is there documented evidence that medication was prescribed (PRN) for the key symptoms that may develop in the last hours and days of life?

I. Pain (missing data $=5,0.1 \%$ )

531481

II. Agitation (missing data $=5,0.1 \%$ )

$4730 \quad 72$

III. Noisy breathing (missing data $=5,0.1 \%$ )

$4258 \quad 65$

$2 b$. Discussions regarding awareness of patients imminent death held with relatives $(n=5722)^{*}$

$3 d$. Discussions regarding the plan of care for the dying phase held with relative/friends or IMCA (missing data=3, $0.05 \%)$

8e. A discussion regarding hydration options/care was undertaken with the relative, following recognition that the patient was expected to die in the coming hours or days $(\mathrm{n}=5722)^{*}$

*Only applicable if patient was recognised by healthcare professional to be dying.

Table 5 Overall impressions of care and support*

Local survey of bereaved relatives $(n=858)$

n

$\%$

29a. How much of the time was s/he treated with respect and dignity in the last 2 days of life? -By doctors $(n=815)$

$\begin{array}{lrc}\text { Always } & 535 & 66 \\ \text { Most of the time } & 105 & 13 \\ \text { Some of the time } & 63 & 8 \\ \text { Never } & 25 & 3 \\ \text { Do not know } & 87 & 11 \\ \text { Missing data } & 43 & 5.0\end{array}$

$29 \mathrm{~b}$. How much of the time was s/he treated with respect and dignity in the last 2 days of life?-By nurses ( $n=823$ )

$\begin{array}{lrc}\text { Always } & 577 & 70 \\ \text { Most of the time } & 131 & 16 \\ \text { Some of the time } & 76 & 9 \\ \text { Never } & 21 & 3 \\ \text { Do not know } & 18 & 2 \\ \text { Missing data } & 35 & 4.1\end{array}$

30. Overall, in your opinion, were you adequately supported during his/her last 2 days of life? $(n=802)$

$\begin{array}{crc}\text { Yes } & 610 & 76 \\ \text { No } & 192 & 24 \\ \text { Missing data } & 56 & 6.5\end{array}$

*Missing data are presented as exact numbers (and percentages) for each of the questions within the tables. The cases of missing data were then excluded from all subsequent analysis and 'valid' percentages were calculated. Hence, the percentages within the tables are $>100 \%$.

formal complaint to the Trust, and so it is likely the proportion of participants perceiving care and support to be poor would be greater. Third, comparison of patient demographic details between the Local
Survey sample and those within the Case Note Review data showed that patients within the Local Survey were more likely to have a cancer diagnosis, although both were similar in terms of representing a predominately elderly population and had an equal gender split. It is noteworthy that when specifically focusing on the patient sample within the Local Survey, over two-thirds had a non-cancer diagnosis; this factor combined with the finding that over half $(56 \%)$ were aged 80 years or above reflects a potentially frailer population, with several comorbidities and a disease trajectory that may be more challenging to predict. By examining all patients who had an 'expected' death within a given time period in hospital, however, this helps provide a closer picture of how care is provided across organisations. Finally, there is debate about whether the bereaved relatives' perceptions are a true reflection of the care provided and in particular, whether or not they would represent the patients' views. These concerns have been discussed before, ${ }^{21}$ but it is accepted that bereaved relatives can provide information about their own experience and support; ${ }^{22}$ often have spent considerable time with the patient; ${ }^{23}$ and as bereavement is an emotional and salient event, are able to recall the events around the time of death. ${ }^{21}$ The concurrence between the bereaved relatives' survey and some key results from the case note review helps support the validity of our findings, especially those relating to aspects of symptom control.

One of the strengths of this study is that direct userrepresentative views complement and add further meaning to the data collected from the NCDAH. This allows additional interpretation of the results and potentially helps direct priorities regarding future care needs. The Local Survey suggests that generic healthcare professionals within acute hospitals may be more confident in the assessment and treatment of symptoms compared with other aspects of holistic care, for example, exploring psychological concerns or information needs. This would be in keeping with other studies, and in particular those which evaluated the use of integrated care pathways within the acute hospital. $^{1424} 25$ In a New Zealand study looking at staff perceptions following implementation of the LCP, one of the most notable reported improvements was in the anticipatory prescribing of medications to help with symptoms. ${ }^{23}$ Within the context of the NCDAH, it is difficult to conclude whether or not the confidence regarding symptom management is due to the legacy left by the LCP; if this is the case, however, it would raise concerns about the sustainability of this aspect of care in the future. Generally, pain seemed to be the symptom that was best controlled, whereas agitation and retained respiratory tract secretions were less well controlled. There may be a number of factors that influenced these findings. Pain is a common symptom and well recognised to occur at the end of $\operatorname{life}^{26}$ and 
healthcare professionals may feel more confident managing this symptom. This may be because it is identified in other clinical situations out with care provided to dying patients, for example, postoperatively. There may be ethical concerns about the use of any medication to help control agitation due to the perceived risk of excessive sedation or a lack of confidence in explaining the rationale for treatment. In particular, concerns about hastening death and euthanasia continue to be debated within media and academic literature. ${ }^{27} 28$ Retained respiratory tract secretions were reported in $\sim 44-56 \%$ of dying patients. ${ }^{29}$ It is recognised that complete control over retained respiratory tract secretions is not always possible and the efficacy of anti-muscarinic drugs is about $80 \%$ of treated patients. ${ }^{29}$ It is noteworthy, however, that anticipatory prescribing to help control this symptom was the lowest compared with others in the case note review and trying to ensure adherence towards anticipatory prescribing for all likely symptoms would potentially be important in optimising good symptom control.

There appeared to be a mismatch between the documented discussions about the recognition of dying with family members and the actual proportion of participants who perceived this discussion occurred. This discrepancy could relate to participants being unable to recall or retain the information. On the other hand, it could suggest that the sample within the Local Survey was not truly representative of the population findings and this may be in part due to the slight difference in the time intervals for the different audit components. Alternatively, this could relate to concerns about the quality and clarity of the communication surrounding these discussions or the difference in perceptions between healthcare professionals and families about these encounters. From the five recommendations published in the recent UK report, 'One chance to get it right', ${ }^{30}$ clear, sensitive, and timely communication is fundamental in ensuring good quality of care is provided to dying patients and their families.

The case note review and the Local Survey suggest that healthcare professionals need to be more proactive when screening for issues and concerns relating to hydration. Misconceptions regarding artificial hydration and the perceived withdrawal of food and fluids in dying patients can be extremely distressing for family members and lead to concerns about whether or not healthcare professionals are hastening death. Hence discussions about this aspect of care are vitally important. Part of the challenge in facilitating these discussions, however, relates to the emotional nature of the subject and because of the limited evidence-base about the benefits and burdens of clinically assisted hydration. ${ }^{31} 32$ Further research to help promote understanding about the management of fluids and hydration for those who are imminently dying is needed. ${ }^{7}$ This in turn would help improve healthcare professionals' confidence and enable discussions with patients and family to be more informative and evidence-based.

Using a Local Survey of Bereaved Relatives' Views within the context of the NCDAH appeared to be a viable and worthwhile additional component. The survey helps provide a snapshot of how dying patients are cared for in acute hospitals as perceived directly by the family members who have undergone this experience. Additionally, the CODE questionnaire has been used within countries out with the UK so has potential to help compare care on an international scale.

Although the survey data are presented as an aggregated data set within this paper, CODE enables direct feedback about the quality of care and level of family support to be given at a Trust level allowing the findings to be interpreted and used at a local level. Key challenges that urgently need addressing on a national scale include enhancing communication skills as a whole and in particular enabling healthcare professionals to address unmet information needs about pertinent end-of-life care issues in a sensitive and informative manner. Delivering an 'individualised care plan', ${ }^{30}$ which is tailored to meet the needs of each patient and their family, is an essential part of optimising the care of the dying within the acute hospital setting.

Acknowledgements The authors wish to thank all the bereaved relatives who participated in this study.

Contributors CRM was involved with the conception, design and conduct of the study, including the development of the CODE questionnaire, providing expert advice regarding the conduct of the bereaved relatives' survey, wrote the statistical analysis plan and drafted and revised the paper. She is the guarantor. HM was involved with the conception, design and conduct of the study, cleaned and analysed the data, and revised the paper. MG was involved with the conception, design and conduct of the study, reviewed the data analysis, and revised the paper. JE was involved with the conception and design of the study, and revised the paper. KS was involved with the conception and design of the study, and revised the paper. All authors gave final approval of the version to be published.

Disclaimer Data used in this report were supplied by the National Care of the Dying Audit for Hospitals which was commissioned by Marie Curie and Public Health England and managed by CEEU, part of the Royal College of Physicians.

Competing interests None declared.

Patient consent No.

Ethics approval The NCDAH concurs with the definition of audit as stipulated by the Health Research Authority and as such, ethical approval was not required. ${ }^{17}$ Participating sites of the Local Survey were advised to ensure the process was compliant with their local Quality Governance Framework.

Provenance and peer review Not commissioned; externally peer reviewed.

Data sharing statement As this was not a clinical trial, routine data sharing would not be undertaken. However, anonymised data would be available for on request from the Royal College of Physicians. 
Open Access This is an Open Access article distributed in accordance with the Creative Commons Attribution Non Commercial (CC BY-NC 4.0) license, which permits others to distribute, remix, adapt, build upon this work noncommercially, and license their derivative works on different terms, provided the original work is properly cited and the use is non-commercial. See: http://creativecommons.org/licenses/by$\mathrm{nc} / 4.0 /$

\section{REFERENCES}

1 Cohen J, Houttekier D, Onwuteaka-Philipsen B, et al. Which patients with cancer die at home? A study of six European countries using death certificate data. J Clin Oncol 2010;28:2267-73.

2 Costantini M, Balzib D, Garronecc E, et al. Geographical variations in place of death among Italian communities suggest an inappropriate hospital use in the terminal phase of cancer disease. Publ Health 2000;114:15-20.

3 Yang L, Sakamoto N, Marui E. A study of home deaths from 1951 to 2002. BMC Palliat Care 2006;5:2.

4 Gomes B, Higginson IJ. Where people die (1974-2030): past trends, future projections and implications for care. Palliat Med 2008;22:33-41.

5 Johnston B. Is effective, person-centred, home based palliative care truly achievable? Palliat Med 2014;28(5)373-4.

6 Clark D, Armstrong M, Allan A, et al. Imminence of death among hospital inpatients: prevalent cohort study. Palliat Med 2014;28:474-9.

7 Department of Health. More care, less pathway. A review of the Liverpool Care Pathway. Department of Health, 2013.

8 Sykes N. The end of the Liverpool Care Pathway. Lancet Oncol 2013;14:926-7.

9 Ellershaw JE, Wilkinson S. Care of the dying. A pathway to excellence. 2nd edn. Oxford: Oxford University Press, 2011.

10 Curtis JR, Patrick DL, Engelberg RA, et al. A measure of the quality of dying and death. Initial validation using after-death interviews with family members. J Pain Symptom Manage 2002;24:17-31.

11 Royal College of Physicians. National Care of the Dying Audit Hospitals. http://www.rcplondon.ac.uk/resources/nationalcare-dying-audit-hospitals (last accessed October 2014).

12 Mayland CR, Lees C, Germain A, et al. Caring for those who die at home: the use and validation of 'Care Of the Dying Evaluation' (CODE) with bereaved relatives. BMJ Support Palliat Care 2014;4:167-74.

13 Mayland CR, Williams EM, Addington-Hall J, et al. Assessing the quality of care for dying patients from the bereaved relatives' perspective: further validation of 'Evaluating Care and Health Outcomes-for the Dying'. J Pain Symp Manage 2014;47:687-96.

14 Mayland CR, Williams EM, Addington-Hall J, et al. Does the 'Liverpool Care Pathway' facilitate an improvement in quality of care for dying cancer patients? Br J Cancer 2013;108:1942-8.

15 Mayland CR, Williams EM, Ellershaw JE. Assessing quality of care for the dying: the development and initial validation of a postal self-completion questionnaire for bereaved relatives. Palliat Med 2012;26:897-907.

16 National end of life care intelligence network. Predicting death. Estimating the proportion of deaths that are 'unexpected'. National end of life care intelligence network. February 2011. http://www.endoflifecare-intelligence.org.uk/ resources/publications/predicting_death (last accessed 14th Sept 2016)

17 Health Research Authority. Defining research. NRES guidance to help you decide if your project requires review by a Research Ethics Committee. http://www.hra.nhs.uk/documents/2013/09/ defining-research.pdf (last accessed 10th Oct 2014).

18 National care of the dying audit for hospitals, England. National report May 2014. London, UK: Royal College of Physicians. https://www.rcplondon.ac.uk/sites/default/files/ ncdah_national_report.pdf (last accessed 22nd Aug 2014).

19 Young AJ, Rogers A, Addington-Hall J. The quality and adequacy of care received at home in the last 3 months of life by people who died following a stroke: a retrospective study of surviving family and friends using the Views of Informal Carers Evaluation of Services questionnaire. Health Soc Care Community 2008;16:419-28.

20 National Survey for Bereaved People (VOICES) 2013. Office for National Statistics. Statistical Bulletin. July. 2014. http:// www.ons.gov.uk/ons/dcp171778_370472.pdf (last accessed 21 Aug 2014).

21 Addington-Hall J, McPherson C. After-death interviews with surrogates/bereaved family members: some issues of validity. J Pain Symptom Manage 2001;22:784-90.

22 Fowler F, Coppola KM, Teno JM. Methodological challenges for measuring quality of care at the end of life. J Pain Sympt Manage 1999;17:114-19.

23 Sneeuw KCA, Aaronson NK, Sprangers MAG, et al. Evaluating the quality of life of cancer patients: assessments by patients, significant others, physicians and nurses. B J Cancer 1999;81:87-94.

24 Clerk JB, Sheward K, Marshall B, et al. Staff perceptions of end-of-life care following implementation of the Liverpool Care Pathway for the Dying Patient in the acute care setting: a New Zealand perspective. J Palliat Med 2012;15:468-73.

25 Veerbeek L, Zuyen LV, Swart SJ, et al. The effect of the Liverpool Care Pathway for the dying: a multi-centre study. Palliat Med 2008;22:145-51.

26 Conill C, Verger E, Henriquez I, et al. Symptom prevalence in the last week of life. J Pain Symptom Manage 1997;14:328-31.

27 George R. Dying people must not lose the most crucial protection. BMJ 2014;349:g4311.

28 Delamothe T, Snow R, Godlee F. Why the Assisted Dying Bill should become law in England and Wales. It's the right thing to do, and most people want it. BMJ 2014;349:g439.

29 Bennett M, Lucas V, Brennan M, et al. Association for Palliative Medicine's Science Committee. Using anti-muscarinic drugs in the management of death rattle: evidence-based guidelines for palliative care. Palliat Med 2002;16:369-74.

30 Leadership Alliance for the care of dying people. One chance to get it right. Improving people's experience of care in the last few days and hours of life. June. 2014. https://www.gov.uk/ government/uploads/system/uploads/attachment_data/file/ 323188/One_chance_to_get_it_right.pdf (last access Sep 2014).

31 Gent M, Fradsham S, Mason SR, et al. What influences towards clinically assisted hydration in the care of dying patients? A review of the literature. BMJ Support Palliat Care 2015;5:223-31.

32 Good P, Cavenagh J, Mather M, et al. Medically assisted hydration for palliative care patients. Cochrane Database Syst Rev 2008;(2):CD006273. 